\title{
Guidelines
}

\section{Portuguese Consensus on Diagnosis, Treatment, and Management of Anemia in Pediatric Inflammatory Bowel Disease}

\author{
Ana Isabel Lopes ${ }^{a}$ b Sara Azevedob José Cabralc ${ }^{c}$ Maria Gomes Ferreirad \\ Piedade Sande-Lemos ${ }^{e}$ Ricardo Ferreira ${ }^{f}$ Eunice Trindade ${ }^{g}$ Rosa Lima ${ }^{\text {h }}$ \\ Henedina Antunes ${ }^{i-k}$ on behalf of the Portuguese Society of Pediatric \\ Gastroenterology, Hepatology and Nutrition (SPGP) - Anemia-IBD Working Group \\ ${ }^{a}$ Faculty of Medicine of the University of Lisbon, Lisbon Academic Medical Centre (CAML), Lisbon, Portugal; \\ ${ }^{b}$ Gastroenterology Unit, Pediatric Department, Hospital de Santa Maria, University Hospital Centre of North Lisbon, \\ Lisbon, Portugal; 'Pediatric Gastroenterology Unit, Dona Estefânia Hospital, University Hospital Centre of Central \\ Lisbon, Lisbon, Portugal; ${ }^{d}$ Pediatric Department, Hospital Garcia de Orta EPE, Almada, Portugal; e Pediatric Department,

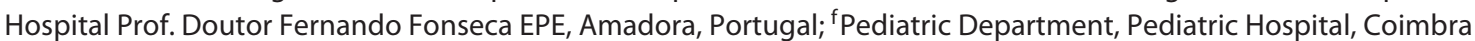 \\ Hospital and Universitary Centre (CHUC), Coimbra, Portugal; 9 Pediatric Gastroenterology Unit, Centro Hospitalar \\ Universitário de São João, Porto, Portugal; ${ }^{h}$ Pediatric Gastroenterology Unit, Centro Materno Infantil do Norte, Porto \\ Hospital and Universitary Centre, Porto, Portugal; 'Pediatric Gastroenterology, Hepatology and Nutrition Unit and \\ Clinical Academic Center 2CA-Braga, Hospital de Braga, Braga, Portugal; ' Life and Health Sciences Institute (ICVS), \\ School of Medicine University of Minho, Braga, Portugal; ${ }^{k} I C V S / 3 B$ 's Associated Laboratory, Braga-Guimarães, Portugal
}

Keywords

Iron-deficiency anemia - Anemia of chronic disease . Inflammatory bowel disease $\cdot$ Childhood · Pediatrics

\section{Abstract}

Anemia is a common extraintestinal manifestation of inflammatory bowel disease (IBD), both in pediatric and in adult patients. Iron deficiency is the main cause of anemia in patients with IBD. Anemia is a clinically relevant comorbidity, with impact on patients' quality of life and it should be timely diagnosed and adequately treated. Currently, an active treatment approach is the recommended strategy, with evidence showing efficacy and safety of intravenous iron formulations. However, evidence in pediatric age remains scarce and no clinical recommendations exist for the diagnosis and treatment of this particular age group. The present document represents the first national consensus on the management of anemia in pediatric IBD and is therefore particularly relevant. The authors anticipate that the proposed recommendations will be useful in daily clinical practice for diagnosing and managing iron deficiency and iron-deficiency anemia in the pediatric population with IBD.

\footnotetext{
(C) 2020 Sociedade Portuguesa de Gastrenterologia Published by S. Karger AG, Basel
}

\section{Consenso Português sobre o Diagnóstico, Tratamento e Abordagem da Anemia na Doença Inflamatória Intestinal Pediátrica}

\section{Palavras Chave}

Anemia por défice de ferro - Anemia por doença crónica . Doença inflamatória intestinal · Infância · Idade Pediátrica

\section{KARGER}

E-Mail karger@karger.com www.karger.com/pjg
(C) 2020 Sociedade Portuguesa de Gastrenterologia Published by S. Karger AG, Basel

Karger

Open access

This article is licensed under the Creative Commons AttributionNonCommercial-NoDerivatives 4.0 International License (CC BYNC-ND) (http://www.karger.com/Services/OpenAccessLicense). Usage and distribution for commercial purposes as well as any distribution of modified material requires written permission.
Ana Isabel Lopes, MD, PhD, Gastroenterology Unit, Pediatric Department Hospital de Santa Maria, University Hospital Centre of North Lisbon and Faculty of Medicine of the University of Lisbon, Lisbon Academic Medical Centre (CAML), Av Professor Egas Moniz, PT-1649-028 Lisbon (Portugal)

E-Mail anaisalopes7@gmail.com 


\section{Resumo}

A anemia é uma manifestação extra-digestiva frequente associada à doença inflamatória intestinal, tanto na população pediátrica como adulta, sendo a anemia por défice de ferro a sua forma mais frequente. Constitui uma comorbilidade clinicamente relevante, com repercussão na qualidade de vida. Deve ser atempadamente diagnosticada e adequadamente tratada. A estratégia terapêutica atualmente aceite preconiza uma atitude interventiva. Neste contexto, a evidência científica atual tem demonstrado a eficácia e segurança da utilização das formulações de ferro endovenoso. Contudo, em idade pediátrica a evidência ainda é insuficiente, não existindo orientações de abordagem diagnóstica ou terapêutica especificamente dirigidas a este grupo etário. Este é o primeiro consenso nacional sobre a abordagem da anemia na doença inflamatória intestinal pediátrica, revestindo-se por isso de particular relevância. Pretende-se que este documento tenha utilidade e aplicabilidade na prática clínica na avaliação e seguimento do défice de ferro e anemia por défice de ferro em doentes pediátricos com doença inflamatória intestinal.

(c) 2020 Sociedade Portuguesa de Gastrenterologia Publicado por S. Karger AG, Basel

\section{Introduction}

Anemia is the most common systemic complication and extraintestinal manifestation of inflammatory bowel disease (IBD), both in pediatric and adult populations [15]. Anemia is a clinically relevant comorbidity, with impact on patients' quality of life and academic and professional capacity, and is associated with high health costs if left undiagnosed and untreated [6-8].

Although several etiologic factors may contribute to the development of anemia in patients with IBD, in most cases IBD-associated anemia is a unique example of the combination of chronic iron deficiency (ID) and anemia of chronic disease (ACD) [8-10]. This distinction is important for the choice of the most appropriate treatment.

The prevalence of anemia in adult IBD patients is variable according to clinical setting - active versus remissive disease [3, 11, 12], inpatients versus outpatients [13] and both ID and iron-deficiency anemia (IDA) have been reported in $16-76 \%$ of adult IBD patients [14]. In fact, the prevalence of anemia at annual follow-up in an adult population-based study in Sweden was 6\% (5\% for patients with ulcerative colitis [UC] and 9\% for those with Crohn's disease [CD], values rising to 35 and 50\%, respectively, in

Portuguese Consensus on Anemia in Pediatric Inflammatory Bowel Disease hospitalization) [13]. In an observational cross-sectional multicenter study including 1,313 adult Portuguese IBD patients with a median follow-up after diagnosis of 7 years, anemia was reported in 244 patients, representing a prevalence of $18.6 \%$ (95\% CI 16.6-20.9) [15]. In another multicenter study including a cohort of 1,871 adult patients, the prevalence of anemia was $49 \%$ in CD patients versus $39 \%$ in UC patients during the first 12 months after diagnosis [16].

In pediatric IBD, the prevalence of anemia is not yet established, with available evidence suggesting a higher prevalence than reported in the adult population. A recent retrospective cohort study in the US including 1,560 CD and 886 UC children reported anemia in 51 and $43 \%$ of patients, respectively [17]. IDA is more frequent in CD, as shown in the study by Azzopardi and Ellul [18], in which 171 adult CD patients were investigated and ID was reported in $78 \%$ of those with active inflammation and $21 \%$ of those with quiescent disease.

The real prevalence of ID and IDA in the pediatric population with IBD remains unknown, with studies reporting higher rates than in the adult population. In 2012, an observational study reported a higher prevalence of ID in children (88\%) and adolescents (83\%) compared with adults (55\%) [3]. In the same year, Wiskin et al. [5] reported an ID prevalence of $70 \%$ in $\mathrm{CD}$ and $65 \%$ in UC pediatric patients 2 years after diagnosis. Recently, a retrospective study of pediatric IBD patients reported a prevalence of IDA or a combination of IDA and ACD of $28.85 \%$ at diagnosis and $15.38 \%$ at the 1 -year follow-up [19]. Another study including pediatric hospitalized patients with IBD reported a $36 \%$ prevalence of IDA [20]. In a population-based retrospective Swedish study, ID was observed in $91 \%$ of children with IBD and remained highly prevalent despite clinical and biochemical remission ( $85 \%$ of ID cases, $34 \%$ of which with IDA) [21].

IBD-associated anemia should be timely diagnosed and adequately treated. Currently, an active treatment approach is the recommended strategy. In adult IBD populations, although safety and efficacy of intravenous (IV) iron formulations have been demonstrated [22-29], it is not clearly established when to use IV iron or the traditional and recent oral iron therapies. Over the last decade, new IV iron formulations have emerged with a more favorable efficacy and safety profile, including iron sucrose and ferric carboxymaltose [30-32]. A recent review suggested that oral iron should be preferred for patients with quiescent IBD disease and mild IDA, while IV iron supplementation should be the best option for patients with active IBD and for those with inadequate response to or 
side effects with oral formulations [33]. In pediatric patients, evidence is still lacking, with no diagnostic or therapeutic guidelines specifically focusing on this age group. Studies investigating IV iron formulations in pediatric patients are scarce $[34,35]$. Recently published studies have shown encouraging data regarding safety and efficacy of the new IV iron formulations - iron sucrose and ferric carboxymaltose - in the treatment of IDA in pediatric patients with IBD $[36,37]$.

Due to the lack of robust data on the management of ID and IDA in pediatric IBD, it is critical to increase clinical experience in the area, with clinical decisions supported by predefined recommendations and multicentric national-based studies.

The latest Portuguese [38] and European (ECCO) [39] consensus statements on the management of ID and anemia in IBD do not specifically address the pediatric population. However, ID is the most common nutritional deficit and IDA the most frequent form of anemia in this age group, and hence the opportunity to assess and monitor children's iron reserves and to investigate ID and IDA diagnosis in this age group should always be assured. The importance of adequate iron reserves at this stage of life is acknowledged, as well as the impact of its deficit in children's cognitive performance, growth, immune regulation, and quality of life $[6,8,40]$.

The goal of this consensus, elaborated by the Portuguese Society of Pediatric Gastroenterology and Nutrition (SPGNP) - Anemia-IBD Working Group, is to propose recommendations for the management of anemia in pediatric patients with IBD, based on ECCO [39] and on the Portuguese [38] consensus on anemia in IBD, specifically focusing on the features of ID and IDA in pediatric age.

\section{Methodology}

The strategy used for this consensus comprised several steps and followed the simplified Delphi procedure methodology [41]. A working group was predefined by selecting nine participants considered to be representative of national reference Pediatric Gastroenterology Centers and with clinical expertise in the area. Three working subgroups (WsG) were subsequently formed: WsG1 focusing on the diagnosis of anemia, WsG2 focusing on the treatment of non-anemia ID and IDA, and WsG3 focusing on monitoring and prevention of ID and IDA and other causes of anemia. Simultaneously, a comprehensive systematic literature review of available evidence about anemia in pediatric and adult (whenever relevant) IBD populations between 2005 and 2018 was performed in PubMed and Medline.

For each WsG, relevant questions were raised based on current clinical practice and on evidence available in the literature, and a preliminary statement document was prepared based on partici-
Table 1. Main causes of anemia in IBD and underlying etiopathogenesis

Iron deficiency anemia

1. Mucosal inflammation

2. Chronic bleeding (gastrointestinal hemorrhage)

3. Reduced absorption

4. Malnutrition

5. Dietary restrictions

Anemia of chronic disease

1. Alterations in distribution of iron stores

2. Immune-mediated alterations of iron transport pathways: reduced iron export from macrophages; functional iron deficiency; iron-deficient erythropoiesis

3. Inhibitory effect of inflammation on erythropoietin

Drug-induced anemia

1. Inhibition of differentiation and proliferation of erythroid precursors

2. Myelosuppression effect (indirect: "antifolic" effect of salazopyrine; direct: azathioprine)

3. Sulfasalazine: folate absorption impairment; hemolysis; aplasia

Vitamin $B_{12}$ and folic acid deficiency

pants' answers to questions raised. The preliminary statement document was reviewed by all participants, with inclusion of suggestions, corrections, and inputs from all the experts. The final voting and consensus took place through face-to-face meeting.

Consensus for each statement was based upon an approval rate $\geq 80 \%$ by the total working group (i.e., at least seven participants), with final possible answers for each statement being "agreement," "disagreement," or "neutral." A $\geq 80 \%$ agreement was reached for every statement. Level of evidence (EL) was graded according to the Oxford Centre for Evidence-Based Medicine (www.cebm.net). Project coordinator Ana Isabel Lopes revised the final document.

\section{Diagnosis of Anemia in IBD}

\section{Definition of Anemia}

Although anemia in IBD is multifactorial, IDA is its most frequent form, followed by ACD (Table 1). Other causes contributing to anemia in IBD include vitamin $\mathrm{B}_{12}$ and folic acid deficiency, as well as adverse effects of certain drugs, as salazopyrine, sulphasalazine, and azathioprine. ID is more common than IDA, as normal hemoglobin $(\mathrm{Hb})$ levels do not necessarily represent adequate iron stores.

Presence of anemia should be actively investigated and patients should be assessed for the presence of anemia throughout the different stages of disease. In pediatric 
Table 2. Minimum hemoglobin and hematocrit levels used to define anemia, according to WHO [50]

\begin{tabular}{lll}
\hline Age/gender & $\begin{array}{l}\text { Hemoglobin, } \\
\mathrm{g} / \mathrm{dL}\end{array}$ & $\begin{array}{l}\text { Hematocrit, } \\
\%\end{array}$ \\
\hline 6 months-5 years & 11.0 & 33 \\
$6-11$ years & 11.5 & 34 \\
$12-13$ years & 12.0 & 36 \\
Young nonpregnant female $\geq 14$ years & 12.0 & 36 \\
Young pregnant female $\geq 14$ years & 11.0 & 33 \\
Young male $\geq 14$ years & 13.0 & 39 \\
\hline
\end{tabular}

age, expected growth spurts and disease-related growth spurts should be considered as a risk factor for ID and/or IDA development.

The World Health Organization (WHO) definition of anemia (Table 2) applies to pediatric IBD patients [42] and referred values should be considered for the diagnosis of anemia. Normal $\mathrm{Hb}$ levels vary according to age and gender, as well as with ethnicity, pregnancy status, altitude, and smoking habits. Interpretation of $\mathrm{Hb}$ and hematocrit levels should take into consideration these modulating factors.

Children and adolescents with IBD have an increased risk of ID due to several causes. Some are not related with IBD, including increased growth requirements, nutritional imbalances due to dietary options, low socioeconomic status, and migrant family context. In IBD, IDA may result from reduced ingestion and absorption, chronic gastrointestinal bleeding, and iron metabolism impairment (functional ID) related with proinflammatory state, as an increase in hepcidin reduces the action of ferroportin and hence iron absorption [43-48].

\section{Statement 1}

The diagnosis of anemia should consider $\mathrm{Hb}$ and hematocrit cut-offs defined by the WHO. All pediatric patients with IBD should be actively assessed for the presence of anemia, independently of disease activity. ( $P e$ diatric EL 4; Adult EL 5)

\section{Diagnosis Workup}

The diagnosis of anemia should be based on laboratory assessment of the following parameters: complete blood count, serum ferritin, transferrin saturation, C-reactive protein (CRP), and erythrocyte sedimentation rate (ESR). The frequency of screening will depend on disease activity and individual risk factors but should not be per-

Portuguese Consensus on Anemia in

Pediatric Inflammatory Bowel Disease formed more than 6 months apart and ideally planned according to periodic disease blood screening $[3,5,49$, 50].

\section{Statement 2}

Investigation of anemia etiology should be initiated when $\mathrm{Hb}$ level is below the lower cut-off for age and gender. The minimum workup includes complete blood count, reticulocyte count, serum ferritin, transferrin saturation, ESR, and CRP. More extensive workup may include other parameters, as serum concentrations of vitamin $B_{12}$, folic acid, haptoglobin, lactate dehydrogenase, creatinine, and urea. Advice from a pediatric hematologist should be considered if the cause of anemia remains unclear after more extensive workup. (Pediatric EL 5)

\section{Diagnosis of ID}

When investigating the underlying cause of anemia, the most probable etiology should be considered. The workup includes red cell distribution width and mean corpuscular volume, mean corpuscular $\mathrm{Hb}$, reticulocyte count, serum ferritin, transferrin saturation, CRP, and ESR. An integrated analysis of these parameters usually enables the diagnosis of IDA and/or ACD $[8,10]$.

The presence of normocytosis indicates ACD, microcytosis indicates IDA (true or functional ID), and macrocytosis indicates vitamin $\mathrm{B}_{12}$ or folic acid deficiency. The mean corpuscular $\mathrm{Hb}$ is a marker of ID and is usually reduced in ID. However, concomitant vitamin $\mathrm{B}_{12}$ and folic acid deficiency and/or azathioprine may elevate this parameter, making it less reliable. Red cell distribution width is usually elevated in IDA and normal in ACD. However, certain factors - as hereditary anemias coexisting in the same patient - may elevate this parameter, making it less useful when isolated.

In IBD, the distinction between IDA and ACD is important, since both conditions typically overlap, and treatment option relies on that distinction. By definition, IDA presents with reduced serum ferritin levels (this being the most important laboratory parameter in clinical practice), reduced serum iron, reduced transferrin saturation, and elevated total iron fixation capacity. However, in the presence of inflammation, serum ferritin is usually elevated. In such cases (high ESR and CRP), serum ferritin $<100 \mu \mathrm{g} / \mathrm{L}$ is considered an appropriate cut-off and is associated with iron depletion. In absence of inflammation, serum ferritin $<30 \mu \mathrm{g} / \mathrm{L}$ indicates ID. In both cases, transferrin saturation $<16 \%$ confirms the diagnosis of ID $[8,10]$. New ID biomarkers are emerging and may be par- 
ticularly useful in cases of active inflammation, allowing a better distinction between IDA and ACD than the one achieved through serum ferritin and transferrin saturation assessment.

Determination of the concentration of soluble transferrin receptor (sTfR) may also be particularly useful. sTfR is a transmembrane protein composed of two identical polypeptide chains stabilized by a disulfide bridge. It circulates in the plasma and its concentration is directly proportional to the total body mass of cellular transferrin receptor [47, 51-53]. sTfR is elevated in plasma in situations of increased bone marrow iron requirements, both in active erythropoietic activity and in ID (true or functional). In the presence of inflammation (whether with normal or elevated ferritin), sTfR elevation is therefore a good indicator of iron-deficient erythropoiesis and IDA. In Portugal, this test is not yet available in most hospitals and hence its widespread use cannot be recommended in clinical practice.

Hepcidin and prohepcidin are iron metabolism regulators, responsible for adjusting the amounts of serum iron according to body requirements. Their usefulness in IBD setting is not definitely established [43-45]. Other markers, as red blood cell size factor $[43,44]$, percentage of hypochromic red cells, and $\mathrm{Hb}$ concentration of reticulocytes, may be useful markers to distinguish between IDA and ACD [39, 45].

When it is not possible to establish the underlying cause of anemia, additional tests may be necessary, including serum concentrations of vitamin $B_{12}$, folic acid, haptoglobin, lactate dehydrogenase, creatinine, and urea, as well as $\mathrm{Hb}$ electrophoresis and peripheral blood smear. If the cause of anemia remains unclear after more extensive workup, advice from a pediatric hematologist is recommended $[8,10]$.

\section{Statement 3}

Diagnostic criteria for ID depend on the presence/ absence of inflammation. In patients with no evidence of active disease, serum ferritin $<30 \mu \mathrm{g} / \mathrm{L}$ is an appropriate criterion. In patients with active disease, serum ferritin $<100 \mu \mathrm{g} / \mathrm{L}$ is consistent with ID. (Adult EL 4)

\section{Diagnosis of $A C D$}

Inflammation has a profound effect on iron metabolism and erythropoiesis. Hepcidin, a hepatic synthesis protein, plays a key role in ACD $[44,48]$. Hepcidin synthesis is reduced during erythropoiesis, assuring iron transport to the bone narrow. Hepcidin synthesis is driven by inflammation, in a process mediated by interleukin
(IL)-6 and involving the JAK/STAT3 pathway [45]. Other inflammatory cytokines, as tumor necrosis factor, may also directly reduce erythropoietin production and inhibit erythropoiesis. The increase in hepcidin, whether by chronic inflammation or by endoplasmic reticulum-associated stress, favors iron depletion in the blood and its retention in the reticuloendothelial system - including in Kupffer cells -, thereby reducing iron transport to erythroblasts, reducing transferrin saturation, and creating a state of functional ID for erythropoiesis [43, 44]. Additionally, hepcidin reduces iron absorption from the duodenum. Inflammatory cytokines also directly reduce erythropoietin production and inhibit erythropoiesis.

All these combined inflammatory mechanisms lead to a functional ID state, characterized by normal or elevated iron stores, reduced transport of iron from the macrophages, low plasma transferrin saturation, and restriction of iron availability in the bone marrow, overall contributing to reduce erythropoiesis. In IBD, the distinction between IDA and ACD is important, as both conditions frequently overlap, and the choice of the appropriate treatment is based on this distinction. Thus, in absence of biochemical or clinical evidence of inflammation, ID is likely if serum ferritin is $<30 \mu \mathrm{g} / \mathrm{L}$. In presence of inflammation, serum ferritin levels can be high despite empty iron stores. In such cases, $100 \mu \mathrm{g} / \mathrm{L}$ is considered an appropriate cut-off level.

\section{Statement 4}

In the presence of biochemical or clinical evidence of inflammation, diagnosis of isolated ACD is based on serum ferritin $>100 \mu \mathrm{g} / \mathrm{L}$ and transferrin saturation $<20 \%$. If serum ferritin level is between 30 and $100 \mu \mathrm{g} / \mathrm{L}$, IDA and ACD likely coexist and IDA should be treated in these patients. (Adult EL 2)

\section{Treatment of ID and IDA in IBD}

In this section, only the therapeutic options for IDA, non-anemia ID, and ACD are addressed. Therapeutic options for vitamin $\mathrm{B}_{12}$ /acid folic deficiency anemia, druginduced anemia, or other causes of anemia are not addressed.

\section{Which Patients to Treat and How to Treat}

Treatment of IDA should be offered to all IBD patients with $\mathrm{Hb}$ levels under the lower limit of normal for age and gender. In the presence of ID, iron supplementation should also be offered. The main goal of treatment is to 
resolve anemia and achieve, at least, the lower limit of normal reference values for serum ferritin, serum iron, and transferrin saturation, assuring adequate iron stores. The lower the baseline $\mathrm{Hb}$ level, the longer the time required to normalize $\mathrm{Hb}$. An increase in $\mathrm{Hb} \geq 2 \mathrm{~g} / \mathrm{dL}$ within 4 weeks of treatment is an acceptable response [8, 39, $49,54]$.

\section{Which Method of Iron Supplementation to Use}

An increasing body of evidence suggests that IV iron formulations are safe and effective in the correction of IDA in pediatric non-IBD populations $[26,55]$. In IBD, the clinical benefit of IV iron is well established in adults, with recent supporting data also emerging in the pediatric population.

Data supporting efficacy and safety of novel IV iron formulations (ferric carboxymaltose and iron sucrose) in the treatment of ID and IDA in pediatric IBD has increased over the last years, with an increasing number of studies reporting correction of anemia and replenishment of adequate iron stores at the end of treatment. Laass and colleagues [26] initially reported the efficacy of ferric carboxymaltose in pediatric patients with IDA and several gastrointestinal conditions by investigating a subgroup of 52 IBD patients ( 29 of which with $C D$ ) with a median age of 11.8 years. Despite its retrospective nature and absence of longterm follow-up, this study documented the efficacy of ferric carboxymaltose in the correction of anemia (median $\mathrm{Hb}$ after treatment: $11.9 \mathrm{~g} / \mathrm{dL}$ ) and its favorable toxicity profile, with no report of adverse effects. In 2016, two studies confirmed these initial results $[36,55]$. The study by Valério de Azevedo et al. [55] prospectively assessed the short-term efficacy and safety of IV iron during 40 months in 19 pediatric patients (median age 15.5 years) with $\mathrm{CD}$ and IDA with remissive/mild disease. The need for retreatment was also assessed by investigators. Results showed a median pre- and post-treatment $\mathrm{Hb}$ of $10.5 \mathrm{~g} / \mathrm{dL}$ and $12.7 \mathrm{~g} / \mathrm{dL}$, respectively, with no major adverse effects. After a median of 15.5 months, $31.5 \%$ of patients required re-treatment. This study reinforced the importance of long-term follow-up of iron status in pediatric CD patients. The study by Danko and Weidkamp [36] prospectively investigated $24 \mathrm{IBD}$ children receiving $3 \mathrm{mg} / \mathrm{kg}$ (up to a maximum dose of $200 \mathrm{mg}$ ) of IV iron sucrose while receiving infliximab. The study showed an increase in mean ferritin, transferrin saturation, and $\mathrm{Hb}$ of 21.9 to 48.8 $\mathrm{ng} / \mathrm{mL}(p=0.0004), 13.2$ to $23.6 \%(p=0.0009)$, and 11.4 to $12.7 \mathrm{~g} / \mathrm{dL}$ ( $p=0.006)$, respectively. At the end of study, 75,63 , and $79 \%$ of patients reached normal values for each parameter, respectively. No adverse reactions to treatment

Portuguese Consensus on Anemia in

Pediatric Inflammatory Bowel Disease were reported. More recently, two studies confirmed the previously observed efficacy and safety data of new-generation IV iron formulations in pediatric patients with IBD $[37,56]$. Stein et al. [37] retrospectively reviewed the charts of all pediatric patients with IBD receiving iron sucrose infusions for IDA at a single center between 2011 and 2015. Seventy-two subjects were included (mostly $[n=53]$ with CD), 43 of which were included in the efficacy analysis. Investigators reported a significant mean $\mathrm{Hb}$ increase throughout the course of treatment, from $9.6 \mathrm{~g} / \mathrm{dL}$ at baseline to $12.1 \mathrm{~g} / \mathrm{dL}$ after iron sucrose therapy $(p<0.001)$. Adverse effects were reported in $18.1 \%$ of subjects and $6.6 \%$ of infusions, none of which life-threatening or requiring hospitalization. The retrospective and single-center study by Papadopoulos et al. [56] analyzed the safety and efficacy outcomes of 41 children with IBD (mostly [56\%] with UC) who received parenteral iron (ferric carboxymaltose, $n=35$; iron sucrose, $n=7$; both, $n=1$ ) over 38 months and showed a mean $2.5 \mathrm{~g} / \mathrm{dL}, 8.4 \mathrm{~g} / \mathrm{dL}$, and $16.2 \%$ increase of $\mathrm{Hb}$, iron levels, and transferrin saturation, respectively. Three children developed mild rash after infusion, which resolved quickly with chlorphenamine. Overall, the published evidence suggests encouraging safety and efficacy of novel IV iron formulations in the treatment of ID and IDA in pediatric patients with IBD.

The latest ECCO guidelines on the management of IDA in IBD recommend IV iron as first-line treatment, due to its safety, efficacy, good tolerability, and fast response $[22,27,39]$. Although oral iron may be an option for mild anemia, it is less effective than IV iron, due to IBD-associated malabsorption [23-25, 28, 29], and requires prolonged administration (minimum 3 months), being often associated with gastrointestinal intolerance [31-33].

Additionally, the effectiveness of treatment with oral iron may be impaired in patients with IBD due to disease activity - which reduces the intestinal iron absorption capacity - and unwanted gastrointestinal effects [34-36]. In patients with active disease, release of hepcidin in response to IL- 6 and IL-1b causes lower iron availability and reduced intestinal absorption of oral iron $[44,57,58]$. Unabsorbed iron is exposed to the ulcerated intestinal surface and may induce mucosal (oxidative) harm. In fact, studies in animal models of IBD have shown that luminal iron may exacerbate disease activity [59-61]. If oral iron is considered a treatment option, the recommended dose is $3-6 \mathrm{mg} / \mathrm{kg}$, up to a maximum of $100 \mathrm{mg} /$ day.

New iron formulations, as ferric maltol, have shown few side effects in adult patients with IBD, even in those with a history of intolerance to ferrous sulfate $[62,63]$. 
Table 3. Simplified scheme for estimation of the ferric carboxymaltose dose to administer

\begin{tabular}{llc}
\hline $\mathrm{Hb}, \mathrm{g} / \mathrm{dL}$ & Body weight $35-70 \mathrm{~kg}$ & Body weight $\geq 70 \mathrm{~kg}$ \\
\hline $10-12$ (female) & $1,000 \mathrm{mg}$ & $1,500 \mathrm{mg}$ \\
$10-13$ (male) & $1,000 \mathrm{mg}$ & $1,500 \mathrm{mg}$ \\
$7-10$ & $1,500 \mathrm{mg}$ & $2,000 \mathrm{mg}$ \\
\hline
\end{tabular}

Dose to administer <35 kg: $15 \mathrm{mg} / \mathrm{kg}$ until a maximum $20 \mathrm{mg} / \mathrm{kg}$ or alternatively use the Ganzoni formula (iron sucrose). Dose to administer for iron deficiency: $500 \mathrm{mg}$ over $35 \mathrm{~kg}$ and $7.5-15 \mathrm{mg} / \mathrm{kg}$ for $<35 \mathrm{~kg}$ (EL 5).

Table 4. Scheme for estimation of the ferric carboxymaltose dose to administer, considering patients with body weight under $35 \mathrm{~kg}$

\begin{tabular}{lllll}
\hline $\mathrm{Hb}, \mathrm{g} / \mathrm{dL}$ & $\mathrm{mmol} / \mathrm{L}$ & Body weight $<35 \mathrm{~kg}$ & Body weight $35-70 \mathrm{~kg}$ & Body weight $>70 \mathrm{~kg}$ \\
\hline$<10$ & $<6.2$ & $500 \mathrm{mg}$ & $1,500 \mathrm{mg}$ & $2,000 \mathrm{mg}$ \\
$10-<14$ & $6.2-<8.7$ & $500 \mathrm{mg}$ & $1,000 \mathrm{mg}$ & $1,500 \mathrm{mg}$ \\
$\geq 14$ & $\geq 8.7$ & $500 \mathrm{mg}$ & $500 \mathrm{mg}$ & $500 \mathrm{mg}$ \\
\hline
\end{tabular}

\section{Statement 5}

IV iron should be considered as first-line treatment for all pediatric IBD patients with $\mathrm{Hb}>6 \mathrm{~g} / \mathrm{dL}$ (with hemodynamic stability and no cardiovascular disease or other comorbidities). Oral iron may be a second-line option for patients with no gastrointestinal symptoms, in remission, with no previous history of oral iron intolerance, and with mild anemia. (Pediatric EL 2b; Adult EL 1)

\section{Iron Formulations Available in Portugal}

Two IV iron formulations are approved by the $\mathrm{Na}-$ tional Authority of Medicines and Health Products (INFARMED) and available in Portugal for use in pediatric age: iron sucrose $(<14$ years) and ferric carboxymaltose ( $\geq 14$ years) [64]. Similarly to iron sucrose, ferric carboxymaltose does not require prior testing and allows the administration of larger amounts of iron in a single dose.

\section{Estimation of IV Iron Dosage Required}

ECCO consensus states that the iron dose to administer should be based on baseline Hb levels and body weight, and the Ganzoni formula (iron deficit [mg] = body weight $[\mathrm{kg}] \times[$ target $\mathrm{Hb}-385$ actual $\mathrm{Hb}][\mathrm{g} / \mathrm{dL}] 386 \times 0.24+$ 500) [65] has been regularly used in the pediatric setting to calculate the IV iron dose to administer. The formula uses body weight to estimate iron store and iron needs, but some studies suggest that it may be error-prone and underestimate iron requirements. Studies also indicate that the simple ferric carboxymaltose dosing schemes (Tables 3 and 4) overestimate dosing requirements compared with the Ganzoni formula [25, 64, 66-68].

The decision to treat ID in patients without anemia and the respective iron formulation to use is controversial in adult recommendations. Some authors propose IV iron formulations for patients with $\mathrm{Hb}<12 \mathrm{~g} / \mathrm{dL}$ and/or serum ferritin $<100 \mu \mathrm{g} / \mathrm{L}$, due to the rapid recurrence of IDA in these patients $[39,66,67]$. The same authors recommend the administration of $500 \mathrm{mg}$ of iron per dose and state that there is insufficient evidence to recommend iron for these patients, although with the new oral iron formulations, it may be considered an option (in remission patients).

\section{Statement 6}

The estimation of iron requirements should be based on baseline $\mathrm{Hb}$ and body weight (>35 kg). (Adult EL 2) The traditional Ganzoni formula may be used for patients $<35 \mathrm{~kg}$. (Adult EL 3b)

\section{Monitoring for Treatment Response to IV Iron}

Response to IV iron supplementation usually occurs within 4-6 weeks of treatment [49]. Hb levels allow to confirm correction of anemia. Effective iron store replenishment may be estimated using a combination of serum ferritin, transferrin saturation, CRP, and/or ERS. The correlation with serum ferritin is not so good, as this therapy induces the synthesis of ferritin and hence, its levels 
may be falsely elevated $[26,45,63]$. ECCO guidelines for the adult population with IBD state that post-treatment serum ferritin levels $>400 \mu \mathrm{g} / \mathrm{L}$ prevent recurrence of ID, suggesting that this value may be an indicator of adequate iron stores $[39,66]$. Due to its only temporary elevation, transferrin saturation is also not a good medium-term indicator.

\section{Statement 7}

Evaluation of response to IV iron therapy and patient follow-up should be performed through complete blood count, CRP, and serum ferritin assessment. These laboratory assessments should be performed within 4 weeks and until 12 weeks after treatment. (Adult EL 4)

\section{Use of Transfusions of Red Cell Concentrates}

The use of red cell concentrate transfusions should be reserved to clinically and hemodynamically unstable patients and/or with $\mathrm{Hb}<6 \mathrm{~g} / \mathrm{dL}$ and should be followed by IV iron treatment $[8,39]$. Additionally, they should be considered for patients with $\mathrm{Hb}<8 \mathrm{~g} / \mathrm{dL}$ in need for a quick therapeutic response (e.g., surgery in the short term) $[8,39]$.

\section{Monitoring and Prevention of ID and IDA Recurrence}

\section{When and How to Monitor Patients for ID and}

Anemia

ID and anemia monitoring in pediatric IBD patients should be included in the laboratory assessment plan according to disease activity $[3,5,39]$. Iron status should be measured every 3 months during the first year after anemia correction, and every 6 months thereafter $[67,69$, 70]. If an adequate $\mathrm{Hb}$ level is not reached after IV iron administration and/or inadequate iron stores persist, monitoring should be performed early and according to patient needs $[67,69]$. In the presence of active disease, laboratory assessment of IDA and/or ID should be timely repeated, along with laboratory disease monitoring.

\section{Statement 8}

Pediatric patients with IBD should be monitored for recurrent ID at least every 3 months during the first year after correction, and every 6 months thereafter. (Pediatric EL 5)

\section{Statement 9}

The laboratory parameters for assessing recurrence of ID include complete blood count, serum ferritin, CRP, and ESR. (Pediatric EL 5)

\section{When to Re-Treat ID and IDA}

According to ECCO consensus, the goal of preventive treatment is to maintain $\mathrm{Hb}$ and serum ferritin levels within the normal range (EL 3) [39]. IDA frequently recurs after treatment. Evidence from the adult population shows that approximately $50 \%$ of patients have recurrence of ID or anemia within 10 months $[66,67]$. The speed of recurrence relates with the size of iron stores after treatment, with post-treatment serum ferritin levels $>400 \mu \mathrm{g} / \mathrm{L}$ reported to prevent ID recurrence within the following $1-5$ years [67].

The FERGImain study introduced the concept of a "proactive" approach to the management of anemia, instead of the traditional "watch and wait" strategy [66]. According to this approach, preventive anemia treatment with IV iron should be initiated as soon as serum ferritin drops below $100 \mu \mathrm{g} / \mathrm{L}[39,49]$. According to the ECCO consensus, after successful treatment of IDA with IV iron, re-treatment with IV iron should be initiated as soon as serum ferritin drops below $100 \mu \mathrm{g} / \mathrm{L}$ or $\mathrm{Hb}$ drops below 12 or $13 \mathrm{~g} / \mathrm{dL}$ (according to gender) (EL 2) [39]. As the prevalence of anemia in children seems to be higher than in adults, both at diagnosis and during follow-up, these recommendations should also be applied when treating pediatric IBD patients. The use of oral iron for re-treatment of pediatric patients with IBD may be considered for cases with mild ID or IDA, with clinically inactive disease, and with no previous intolerance to oral iron (see Statement 8). No studies are available to date on the efficacy of oral iron in prevention of ID or IDA in pediatric IBD.

\section{Statement 10}

After correction of ID/IDA with IV iron, re-treatment should be considered for patients with anemia recurrence (serum ferritin $<100 \mu \mathrm{g} / \mathrm{L}$ or $\mathrm{Hb}$ under the lower limit of normal for age and gender). IV iron formulations are the first-line treatment. Oral iron may also be an option. (Adult EL 2)

In pediatric age, the clinical approach largely relies in controlling the inflammatory activity of the disease and waiting for correction of anemia. However, studies have shown that the speed of anemia correction is too slow and a proactive approach should be adopted instead of a 
watchful one [26]. Rapid anemia recurrence should raise clinical suspicion of inflammatory activity and adequate treatment should be promptly started. Coexisting IDA and $\mathrm{ACD}$ is frequent in these patients. Active treatment of IBD with the goal of maintaining disease remission leads to IDA/ACD resolution $[8,39,49]$.

\section{Statement 11}

A rapid recurrence of anemia should raise clinical suspicion of IBD activity and prompt early assessment of disease activity and treatment initiation/escalation in parallel with anemia treatment. (Pediatric EL 5)

ECCO guidelines recommend the use of erythropoiesis-stimulating agents (erythropoietin, darbopoietin) in patients with IBD and anemia who have not responded satisfactorily to the therapy with IV iron [39]. This recommendation is supported by studies in rheumatologic patients with IDA receiving treatment with anti-tumor necrosis factor antibodies and also in patients with IBD. However, evidence in the pediatric population is still absent.

\section{Statement 12}

To date, there is no evidence on the use of erythropoiesis-stimulating agents in the treatment of IDA refractory to treatment with IV iron in the pediatric IBD population. (Pediatric EL 5)

\section{Management of Non-ID Anemia}

IDA usually presents with microcytosis (or normocytosis if associated with ACD) and normal or reduced reticulocytes. Consequently, assessment of these parameters requires a different characterization, since the etiology may not be obvious. The etiology of anemia in IBD is multifactorial, with the most frequent causes being IDA and ACD. Other causes are less frequent but should also be considered, including vitamin $\mathrm{B}_{12}$ and folic acid defi- ciency, adverse effects of certain drugs (thiopurines, methotrexate), infections, or myelodysplastic syndromes. Patients submitted to small bowel resection or with severe small bowel disease require closer surveillance and should be annually monitored for serum levels of vitamin $B_{12}$ and folic acid, or sooner if macrocytosis is present and subjects are not receiving purine analogues. Mean corpuscular volume and reticulocyte count are important parameters for the management of non-IDA, as they allow distinguishing this condition from macrocytic anemia with low reticulocyte count (vitamin $\mathrm{B}_{12}$ and folic acid deficiency, medications, myelodysplastic syndrome) [69].

\section{Statement 13}

The characterization of non-ID anemia should be performed based on mean corpuscular volume and reticulocyte count. (Adult EL 5)

\section{Acknowledgments}

The authors acknowledge Dr. Joana Cavaco Silva (ScienceCircle) for manuscript edition.

\section{Disclosure Statement}

The authors have no conflicts of interest to declare.

\section{Funding Sources}

This manuscript received funding support from Vifor Pharma.

\section{Author Contributions}

Conception/design and supervision: Ana Isabel Lopes. Literature review, manuscript writing, critical review, and final approval of manuscript: Ana Isabel Lopes, Sara Azevedo, José Cabral, Maria Gomes Ferreira, Piedade Sande-Lemos, Ricardo Ferreira, Eunice Trindade, Rosa Lima, Henedina Antunes.

\section{References}

1 Gerasimidis K, Barclay A, Papangelou A, Missiou D, Buchanan E, Tracey C, et al. The epidemiology of anemia in pediatric inflammatory bowel disease: prevalence and associated factors at diagnosis and follow-up and the impact of exclusive enteral nutrition. Inflamm Bowel Dis. 2013 Oct;19(11):2411-22.
2 Gisbert JP, Gomollón F. Common misconceptions in the diagnosis and management of anemia in inflammatory bowel disease. Am J Gastroenterol. 2008 May;103(5):1299-307.

3 Goodhand JR, Kamperidis N, Rao A, Laskaratos F, McDermott A, Wahed M, et al. Prevalence and management of anemia in children, adolescents, and adults with inflammatory bowel disease. Inflamm Bowel Dis. 2012 Mar; 18(3):513-9.

4 Ott C, Schölmerich J. Extraintestinal manifestations and complications in IBD. Nat Rev Gastroenterol Hepatol. 2013 Oct;10(10):58595. 
5 Wiskin AE, Fleming BJ, Wootton SA, Beattie RM. Anaemia and iron deficiency in children with inflammatory bowel disease. J Crohn's Colitis. 2012 Jul;6(6):687-91.

6 Agaoglu L, Torun O, Unuvar E, Sefil Y, Demir D. Effects of iron deficiency anemia on cognitive function in children. Arzneimittelforschung. 2007;57 6A:426-30.

7 Ershler WB, Chen K, Reyes EB, Dubois R. Economic burden of patients with anemia in selected diseases. Value Health. 2005 NovDec;8(6):629-38.

8 Reinisch W, Staun M, Bhandari S, Muñoz M. State of the iron: how to diagnose and efficiently treat iron deficiency anemia in inflammatory bowel disease. J Crohn's Colitis. 2013 Jul;7(6):429-40.

9 Gomollón F, Gisbert JP. Anemia and inflammatory bowel diseases. World J Gastroenterol. 2009 Oct;15(37):4659-65.

10 Stein J, Hartmann F, Dignass AU. Diagnosis and management of iron deficiency anemia in patients with IBD. Nat Rev Gastroenterol Hepatol. 2010 Nov;7(11):599-610.

11 Ott C, Liebold A, Takses A, Strauch UG, Obermeier F. High prevalence but insufficient treatment of iron-deficiency anemia in patients with inflammatory bowel disease: results of a population-based cohort. Gastroenterol Res Pract. 2012;2012:595970.

12 Sjöberg D, Holmström T, Larsson M, Nielsen AL, Holmquist L, Rönnblom A. Anemia in a population-based IBD cohort (ICURE): still high prevalence after 1 year, especially among pediatric patients. Inflamm Bowel Dis. 2014 Dec;20(12):2266-70.

13 Rejler M, Tholstrup J, Andersson-Gäre B, Spångéus A. Low prevalence of anemia in inflammatory bowel disease: a populationbased study in Sweden. Scand J Gastroenterol. 2012 Sep;47(8-9):937-42.

14 Akpınar H, Çetiner M, Keshav S, Örmeci N, Törüner M. Diagnosis and treatment of iron deficiency anemia in patients with inflammatory bowel disease and gastrointestinal bleeding: iron deficiency anemia working group consensus report. Turk J Gastroenterol. 2017 Mar;28(2):81-7.

15 Portela F, Lago P, Cotter J, Gonçalves R, Vasconcelos H, Ministro P, et al.; CAPOR Investigators and GEDII. Anaemia in Patients with Inflammatory Bowel Disease - A Nationwide Cross-Sectional Study. Digestion. 2016;93(3): 214-20.

16 Burisch J, Vegh Z, Katsanos KH, Christodoulou DK, Lazar D, Goldis A, et al.; EpiCom study group. Occurrence of Anaemia in the First Year of Inflammatory Bowel Disease in a European Population-based Inception Cohort-An ECCO-EpiCom Study. J Crohn's Colitis. 2017 Oct;11(10):1213-22.

17 Miller SD, Cuffari C, Akhuemonkhan E, Guerrerio AL, Lehmann H, Hutfless S. Anemia Screening, Prevalence, and Treatment in Pediatric Inflammatory Bowel Disease in the United States, 2010-2014. Pediatr Gastroenterol Hepatol Nutr. 2019 Mar;22(2):152-61.
18 Azzopardi N, Ellul P. Iron deficiency in Crohn's disease: iron supplementation or disease control? J Crohn's Colitis. 2014 Oct; 8(10): 1333

19 Aljomah G, Baker SS, Schmidt K, Alkhouri R, Kozielski R, Zhu L, et al. Anemia in Pediatric Inflammatory Bowel Disease. J Pediatr Gastroenterol Nutr. 2018 Sep;67(3):351-5.

20 Krawiec P, Pac-Kożuchowska E. Soluble transferrin receptor and soluble transferrin receptor/log ferritin index in diagnosis of iron deficiency anemia in pediatric inflammatory bowel disease. Dig Liver Dis. 2019 Mar;51(3):352-7.

21 Wikholm E, Malmborg P, Forssberg M, Hederos CA, Wikström S. Iron Deficiency Is Common During Remission in Children With Inflammatory Bowel Disease. Glob PediatrHealth.2016Mar4;3:2333794X16633672.

22 Auerbach M, Ballard H. Clinical use of intravenous iron: administration, efficacy, and safety. Hematology (Am Soc Hematol Educ Program). 2010;2010(1):338-47.

23 Erichsen K, Ulvik RJ, Nysaeter G, Johansen J, Ostborg J, Berstad A, et al. Oral ferrous fumarate or intravenous iron sucrose for patients with inflammatory bowel disease. Scand J Gastroenterol. 2005 Sep;40(9):1058-65.

24 Gisbert JP, Bermejo F, Pajares R, Pérez-Calle JL, Rodríguez M, Algaba A, et al. Oral and intravenous iron treatment in inflammatory bowel disease: hematological response and quality of life improvement. Inflamm Bowel Dis. 2009 Oct; 15(10):1485-91.

25 Kulnigg S, Stoinov S, Simanenkov V, Dudar LV, Karnafel W, Garcia LC, et al. A novel intravenous iron formulation for treatment of anemia in inflammatory bowel disease: the ferric carboxymaltose (FERINJECT) randomized controlled trial. Am J Gastroenterol. 2008 May; 103(5):1182-92.

26 Laass MW, Straub S, Chainey S, Virgin G, Cushway T. Effectiveness and safety of ferric carboxymaltose treatment in children and adolescents with inflammatory bowel disease and other gastrointestinal diseases. BMC Gastroenterol. 2014 Oct;14(1):184.

27 Lee TW, Kolber MR, Fedorak RN, van Zanten $\mathrm{SV}$. Iron replacement therapy in inflammatory bowel disease patients with iron deficiency anemia: a systematic review and metaanalysis. J Crohn's Colitis. 2012 Apr;6(3): 267-75.

28 Lindgren S, Wikman O, Befrits R, Blom H, Eriksson A, Grännö C, et al. Intravenous iron sucrose is superior to oral iron sulphate for correcting anaemia and restoring iron stores in IBD patients: A randomized, controlled, evaluator-blind, multicentre study. Scand J Gastroenterol. 2009;44(7):838-45.

29 Schröder O, Mickisch O, Seidler U, de Weerth A, Dignass AU, Herfarth $\mathrm{H}$, et al. Intravenous iron sucrose versus oral iron supplementation for the treatment of iron deficiency anemia in patients with inflammatory bowel disease-a randomized, controlled, open-label, multicenter study. Am J Gastroenterol. 2005 Nov; 100(11):2503-9.
30 Anker SD, Comin Colet J, Filippatos G, Willenheimer R, Dickstein K, Drexler H, et al.; FAIR-HF Trial Investigators. Ferric carboxymaltose in patients with heart failure and iron deficiency. N Engl J Med. 2009 Dec;361(25): 2436-48.

31 Covic A, Mircescu G. The safety and efficacy of intravenous ferric carboxymaltose in anaemic patients undergoing haemodialysis: a multi-centre, open-label, clinical study. Nephrol Dial Transplant. 2010 Aug;25(8): 2722-30.

32 Van Wyck DB, Mangione A, Morrison J, Hadley PE, Jehle JA, Goodnough LT. Largedose intravenous ferric carboxymaltose injection for iron deficiency anemia in heavy uterine bleeding: a randomized, controlled trial. Transfusion. 2009 Dec;49(12):2719-28.

33 Nielsen $\mathrm{OH}$, Soendergaard C, Vikner ME, Weiss G. Rational Management of Iron-Deficiency Anaemia in Inflammatory Bowel Disease. Nutrients. 2018 Jan;10(1):82.

34 Moorani KN, Asim S. Parenteral iron sucrose in iron deficiency anaemia of paediatric chronic kidney disease. J Ayub Med Coll Abbottabad. 2011 Jul-Sep;23(3):47-50.

35 Pinsk V, Levy J, Moser A, Yerushalmi B, Kapelushnik J. Efficacy and safety of intravenous iron sucrose therapy in a group of children with iron deficiency anemia. Isr Med Assoc J. 2008 May;10(5):335-8.

36 Danko I, Weidkamp M. Correction of Iron Deficiency Anemia With Intravenous Iron Sucrose in Children With Inflammatory Bowel Disease. J Pediatr Gastroenterol Nutr. 2016 Nov;63(5):e107-11.

37 Stein RE, Plantz K, Maxwell EC, Mamula P, Baldassano RN. Intravenous Iron Sucrose for Treatment of Iron Deficiency Anemia in Pediatric Inflammatory Bowel Disease. J Pediatr Gastroenterol Nutr. 2018 Feb;66(2):e51-5.

38 Magro F, Ramos J, Correia L, Lago P, Peixe P, Gonçalves AR, et al. [Portuguese Consensus on the Diagnosis, Prevention and Treatment of Anaemia in Inflammatory Bowel Disease]. Acta Med Port. 2016 Feb;29(2):144-56.

39 Dignass AU, Gasche C, Bettenworth D, Birgegård G, Danese S, Gisbert JP, et al.; European Crohn's and Colitis Organisation [ECCO]. European consensus on the diagnosis and management of iron deficiency and anaemia in inflammatory bowel diseases. J Crohn's Colitis. 2015 Mar;9(3):211-22.

40 Domellöf M, Braegger C, Campoy C, Colomb V, Decsi T, Fewtrell M, et al.; ESPGHAN Committee on Nutrition. Iron requirements of infants and toddlers. J Pediatr Gastroenterol Nutr. 2014 Jan;58(1):119-29.

41 Fink A, Kosecoff J, Chassin M, Brook RH. Consensus methods: characteristics and guidelines for use. Am J Public Health. 1984 Sep;74(9):979-83.
Portuguese Consensus on Anemia in Pediatric Inflammatory Bowel Disease
GE Port J Gastroenterol 2020;27:244-254 DOI: $10.1159 / 000505071$ 
42 World Health Organization. Haemoglobin concentrations for the diagnosis of anaemia and assessment of severity. Vitamin and Mineral Nutrition Information System. Geneva. 2011 ; (WHO/NMH/NHD/MNM/11.1). Available from: https://www.academia. edu/4215770/WHO._Haemoglobin_concentrations_for_the_diagnosis_of_anaemia and_assessment_of_severity._Vitamin_and_ Mineral_Nutrition_Information_System. Geneva_World_Health_Organization_2011 $\mathrm{WHO}_{-} \mathrm{NMH}_{-} \mathrm{NHD}_{-}$ MNM_11.1

43 Porto G, Oliveira S, Pinto JP. Hepcidina: A Molécula-Chave na Regulação do Metabolismo do Ferro. J Port Gastrenterologia. 2012; 19:26-32.

44 Nemeth E, Tuttle MS, Powelson J, Vaughn MB, Donovan A, Ward DM, et al. Hepcidin regulates cellular iron efflux by binding to ferroportin and inducing its internalization. Science. 2004 Dec;306(5704):2090-3.

45 Vermeulen E, Vermeersch P. Hepcidin as a biomarker for the diagnosis of iron metabolism disorders: a review. Acta Clin Belg. 2012 May-Jun;67(3):190-7.

46 Wrighting DM, Andrews NC. Interleukin-6 induces hepcidin expression through STAT3. Blood. 2006 Nov; 108(9):3204-9.

47 Oustamanolakis P, Koutroubakis IE, Kouroumalis EA. Diagnosing anemia in inflammatory bowel disease: beyond the established markers. J Crohn's Colitis. 2011 Oct; 5(5):381-91.

48 Girelli D, Nemeth E, Swinkels DW. Hepcidin in the diagnosis of iron disorders. Blood. 2016 Jun;127(23):2809-13.

49 Gasche C, Berstad A, Befrits R, Beglinger C, Dignass A, Erichsen K, et al. Guidelines on the diagnosis and management of iron deficiency and anemia in inflammatory bowel diseases. Inflamm Bowel Dis. 2007 Dec;13(12):154553.

50 World Health Organization (WHO). Iron Deficiency Anaemia - Assessment, Prevention, and Control. A guide for programme managers. WHO/NHD/01.3. 2001. Available from: http://www.who.int/nutrition/publications/en/ida_assessment_prevention_control.pdf

51 Abitbol V, Borderie D, Polin V, Maksimovic F, Sarfati G, Esch A, et al. Diagnosis of Iron Deficiency in Inflammatory Bowel Disease by Transferrin Receptor-Ferritin Index. Medicine (Baltimore). 2015 Jul;94(26):e1011.
52 Niepel D, Klag T, Malek NP, Wehkamp J. Practical guidance for the management of iron deficiency in patients with inflammatory bowel disease. Therap Adv Gastroenterol. 2018 Apr;11:1756284818769074.

53 Oustamanolakis P, Koutroubakis IE. Soluble transferrin receptor-ferritin index is the most efficient marker for the diagnosis of iron deficiency anemia in patients with IBD. Inflamm Bowel Dis. 2011 Dec;17(12):E158-9.

54 Gasche C, Waldhoer T, Feichtenschlager T, Male C, Mayer A, Mittermaier C, et al.; Austrian Inflammatory Bowel Diseases Study Group. Prediction of response to iron sucrose in inflammatory bowel disease-associated anemia. Am J Gastroenterol. 2001 Aug;96(8): 2382-7.

55 Valério de Azevedo S, Maltez C, Lopes AI. Pediatric Crohn's disease, iron deficiency anemia and intravenous iron treatment: a followup study. Scand J Gastroenterol. 2017 Jan; 52(1):29-33.

56 Papadopoulos M, Patel D, Korologou-Linden R, Goto E, Soondrum K, Fell JM, et al. Safety and efficacy of parenteral iron in children with inflammatory bowel disease. Br J Clin Pharmacol. 2018 Apr;84(4):694-9.

57 Arndt S, Maegdefrau U, Dorn C, Schardt K, Hellerbrand C, Bosserhoff AK. Iron-induced expression of bone morphogenic protein 6 in intestinal cells is the main regulator of hepatic hepcidin expression in vivo. Gastroenterology. 2010 Jan;138(1):372-82.

58 Stein J, Dignass AU. Management of iron deficiency anemia in inflammatory bowel disease - a practical approach. Ann Gastroenterol. 2013;26(2):104-13.

59 Oldenburg B, van Berge Henegouwen GP, Rennick D, Van Asbeck BS, Koningsberger JC. Iron supplementation affects the production of pro-inflammatory cytokines in IL-10 deficient mice. Eur J Clin Invest. 2000 Jun; 30(6):505-10.

60 Seril DN, Liao J, Ho KL, Warsi A, Yang CS, Yang GY. Dietary iron supplementation enhances DSS-induced colitis and associated colorectal carcinoma development in mice. Dig Dis Sci. 2002 Jun;47(6):1266-78.
61 Seril DN, Liao J, West AB, Yang GY. Highiron diet: foe or feat in ulcerative colitis and ulcerative colitis-associated carcinogenesis. J Clin Gastroenterol. 2006 May-Jun;40(5):3917.

62 Schmidt C, Ahmad T, Tulassay Z, Baumgart DC, Bokemeyer B, Howaldt S, et al.; AEGIS Study Group. Ferric maltol therapy for iron deficiency anaemia in patients with inflammatory bowel disease: long-term extension data from a Phase 3 study. Aliment Pharmacol Ther. 2016 Aug;44(3):259-70.

63 Stallmach A, Büning C. Ferric maltol (ST10): a novel oral iron supplement for the treatment of iron deficiency anemia in inflammatory bowel disease. Expert Opin Pharmacother. 2015;16(18):2859-67.

64 Infarmed. Resumo das Características do Medicamento (RCM). Ferinject.

65 Ganzoni AM. [Intravenous iron-dextran: therapeutic and experimental possibilities]. Schweiz Med Wochenschr. 1970 Feb;100(7): 301-3.

66 Evstatiev R, Alexeeva O, Bokemeyer B, Chopey I, Felder M, Gudehus M, et al.; FERGI Study Group. Ferric carboxymaltose prevents recurrence of anemia in patients with inflammatory bowel disease. Clin Gastroenterol Hepatol. 2013 Mar;11(3):269-77.

67 Kulnigg S, Teischinger L, Dejaco C, Waldhör $\mathrm{T}$, Gasche C. Rapid recurrence of IBD-associated anemia and iron deficiency after intravenous iron sucrose and erythropoietin treatment. Am J Gastroenterol. 2009 Jun;104(6): 1460-7.

68 Reinisch W, Staun M, Tandon RK, Altorjay I, Thillainayagam AV, Gratzer C, et al. A randomized, open-label, non-inferiority study of intravenous iron isomaltoside 1,000 (Monofer) compared with oral iron for treatment of anemia in IBD (PROCEED). Am J Gastroenterol. 2013 Dec;108(12):1877-88.

69 Lee T, Clavel T, Smirnov K, Schmidt A, Lagkouvardos I, Walker A, et al. Oral versus intravenous iron replacement therapy distinctly alters the gut microbiota and metabolome in patients with IBD. Gut. 2017 May;66(5):86371.

70 Pels LP, Van de Vijver E, Waalkens HJ, Uitentuis J, JGonera-de ong G, van Overbeek LA, et al. Slow hematological recovery in children with IBD-associated anemia in cases of "expectant management". J Pediatr Gastroenterol Nutr. 2010 Dec;51(6):708-13. 